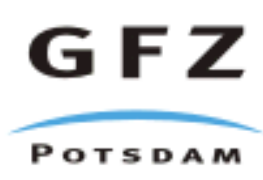

Originally published as:

Bauer, K., Pratt, R. G., Haberland, C., Weber, M. (2008): Neural network analysis of crosshole tomographic images: The seismic signature of gas hydrate bearing sediments in the Mackenzie Delta (NW Canada). - Geophysical Research Letters, 35, L19306

DOI: 10.1029/2008GL035263 


\title{
Neural network analysis of crosshole tomographic images: The seismic signature of gas hydrate bearing sediments in the Mackenzie Delta (NW Canada)
}

\author{
Bauer, K., GFZ Potsdam, Germany \\ Pratt, R.G., Queen’s University, Kingston, Ontario, Canada \\ Haberland, C., GFZ Potsdam \\ Weber, M., GFZ Potsdam
}

\begin{abstract}
Crosshole seismic experiments were conducted to study the in-situ properties of gas hydrate bearing sediments (GHBS) in the Mackenzie Delta (NW Canada). Seismic tomography provided images of P velocity, anisotropy, and attenuation. Self-organizing maps (SOM) are powerful neural network techniques to classify and interpret multi-attribute data sets. The coincident tomographic images are translated to a set of data vectors in order to train a Kohonen layer. The total gradient of the model vectors is determined for the trained SOM and a watershed segmentation algorithm is used to visualize and map the lithological clusters with well-defined seismic signatures. Application to the Mallik data reveals four major litho-types: (1) GHBS, (2) sands, (3) shale/coal interlayering, and (4) silt. The signature of seismic P wave characteristics distinguished for the GHBS (high velocities, strong anisotropy and attenuation) is new and can be used for new exploration strategies to map and quantify gas hydrates.
\end{abstract}

\section{Introduction}

Gas hydrates (GH) are ice-like substances formed by open lattices of water molecules which physically surround methane or other gas molecules without chemical connections [Sloan, 1998]. Predominantly methane hydrates are found widespread offshore along the continental 
margins and in terrestrial hydrocarbon basins with thick permafrost covers. Major controlling factors for the GH formation include sufficient supply of biogenic or thermogenic gas, sequestration in porous sediments, and well-defined pressure and temperature conditions. As GH are considered as potential future energy resources, and important factors in greenhouse global warming scenarios, there is a strong demand for geophysical, mostly seismic, methods to detect and map the distribution and to estimate the volumes of GH. The development of methods specifically suited for such tasks requires comprehensive knowledge about the insitu seismic signatures of GHBS.

Crosshole seismic measurements carried out in the Mackenzie Delta (NW Canada) revealed unique insights into the in-situ properties of the GHBS [Bauer et al., 2005a,b; Pratt et al., 2005]. Ray-based tomographic methods provided coincident images of seismic P velocity, anisotropy, and attenuation for the GH interval. A combined interpretation of these parameters is here carried out by the application of Artificial Neural Networks (ANN). ANN are mathematical models of information processing based on general principles of biological neural systems behaviour (parallel processing, adaptive learning, generalization). ANN were used for the lithological classification of seismic tomograms in geological exploration during tunnel construction [Klose, 2006], and in local earthquake tomography [Tselentis et al., 2007]. To our knowledge, this is the first time ANN methods are used for tomographic data interpretation in relation with GH characterization.

\section{Mallik 2002 Project and Geological Setting}

The Mallik project was carried out in winter 2002 on Richard Island in the outer Mackenzie Delta, in the Canadian Arctic. One main well 5L-38 and two observation wells 3L-38 and 4L38 were drilled to depths of $1160 \mathrm{~m}$. The scientific program included coring, sedimentological, geochemical and geophysical field work, in addition to laboratory 
measurements to study the in-situ properties of the GHBS. Small-scale production tests were conducted by pressure-drawdown and thermal stimulation [Dallimore and Collett, 2005].

The occurrence of GH in the study area is well-known since first findings in industry boreholes in the early 1970's [Bily and Dick, 1974]. A $600 \mathrm{~m}$ thick permafrost layer is the essential controlling factor for the stability of the GH, which deposit between $900 \mathrm{~m}$ and 1100 m depth. The lithology is dominated by unconsolidated and lithified sands, silts and shales of the Miocene and Oligocene sequences (Mackenzie Bay Sequence, 346-926 m, Kugmallit Sequence, 926-1150 m) which were deposited in fluvio-deltaic environments [Medioli et al., 2005]. GH are highly concentrated in several, 5 m - 40 m thick sand layers with $25 \%$ - $40 \%$ porosity, where the GH typically occupies $50 \%-90 \%$ of the pore space [Dallimore and Collett, 2005]. The GH was predominantly formed by thermogenic methane gas which migrated from depths below 5000 m [Lorenson et al., 2005]. Only small hydrocarbon gas volumes are found below the present stability zone [Wiersberg et al., 2005]. This could be the reason for the weak reflection related with the bottom of the GH zone (bottom-simulating reflector, BSR) in regional reflection seismic data [Collett et al., 1999].

\section{Crosshole Seismic Tomography}

The crosshole tomography conducted in Mallik was the first experiment of this kind to study the in-situ seismic properties of GHBS. A 2-D cross section of $90 \mathrm{~m}$ width was covered between $800 \mathrm{~m}$ and $1150 \mathrm{~m}$ depth [Bauer et al., 2005b]. The processing included ray-based [Bauer et al., 2005a] and waveform inversion [Pratt et al., 2005] to determine the seismic properties of the GHBS, and time lapse analysis to detect production test effects [Watanabe et al., 2005].

Figure 1 shows the images of $\mathrm{P}$ velocity, anisotropy, and inelastic attenuation [Bauer et al., 2005a]. Travel time data were used for a damped least-squares inversion [Thurber, 1983] to 
determine the isotropic P velocities (Figure 1a). An anisotropic-velocity tomography [Pratt and Chapman, 1992] was applied assuming transverse isotropy (TI) with a vertical axis of symmetry (VTI). This is a common model for sub-horizontally layered sediments. In tomographic experiments with seismic wave lengths much larger than the scale of the layering, measured velocities are typically higher in the horizontal than in the vertical direction. The anisotropy factor $\varepsilon$ (Figure 1 b) refers to the difference between the horizontal and the vertical velocities, normalized by the horizontal velocity. The quality factor $Q_{p}$ is inversely related to the inelastic attenuation of $\mathrm{P}$ waves (Figure 1c). Path-average attenuation was calculated from the spectral decay of the first arrival wave-forms and inverted similar to the travel times [Thurber, 1983; Rietbrock, 1996].

The visual comparison of Figures 1a-c reveals qualitative correlations of the three attributes. The zones with high GH concentrations in well 5L-38 (Figure 1d) are characterized by higher velocity, stronger anisotropy and stronger attenuation, in contrast to the GH free sediments. A quantitative evaluation of these patterns can be achieved by ANN analysis.

\section{Neural Network Method}

ANN can be used for classification problems representing a major topic in pattern recognition, where objects are classified by characteristic properties spanning a multidimensional parameter space. For our application, the parameter space is defined by seismic $\mathrm{P}$ velocities, anisotropy, and attenuation, and the objects to be classified represent the tomographic grid cells. ANN analysis includes training and application of the learned knowledge. Training can be carried out supervised or unsupervised. The latter does not require information about the output when the input examples are presented to the network. We used the unsupervised approach of the self-organizing feature map (SOM, Kohonen [1995]). This allows a topological projection of the input space onto a 2-dimensional model 
map, where neighboring regions are related with similar input properties. This can be used for data clustering and classification.

Figure 2 describes the schematic working flow for a synthetic test. The input data consist of 3 images from a hypothetic experiment comparable with the application from the Mackenzie Delta (Figure 2a). The model consists of 8,000 cells and is constructed by several layers with well-defined seismic properties. $10 \%$ random noise was added to simulate a more realistic situation. During the iterative training (Figure 2b), any tomographic cell is chosen randomly at iteration $t$, and a data vector is formed by the corresponding values of seismic P velocity $v_{p}(t)$, anisotropy $\varepsilon(t)$, and attenuation $100 / Q_{p}(t)$ :

$$
\vec{x}(t)=\left(v_{p}(t), \quad \varepsilon(t), \quad 100 / Q_{p}(t)\right)^{T}
$$

After a normalisation procedure the data vector serves as input for the Kohonen layer which is a 2-dimensional arrangement of neurons. The two dimensions have no physical meaning but are introduced to allow for the topological ordering of the input data. The number of neurons may range from a few dozen to several thousands, where in most applications it is chosen much smaller than the total number of data vectors. For the relative size of the two axes, Kohonen [1995] suggested to use the ratio of the two largest eigenvalues from the covariance matrix analysis (CMA) of the input data (e.g., 20 by 10 neurons, Figure 2b).

When the training is started, each neuron $i$ is associated with a n-dimensional model vector $\vec{m}_{i}(t)$ (in this example 3 components), where the values are set randomly. The best-matching, so-called winning neuron $b$ with the model vector $\vec{m}_{b}(t)$ most similar to the input vector $\vec{x}(t)$ is determined based on the condition:

$$
\forall i, \quad\left\|\vec{x}(t)-\vec{m}_{b}(t)\right\| \leq\left\|\vec{x}(t)-\vec{m}_{i}(t)\right\| .
$$


The model vectors of all neurons are then updated using the learning rule

$$
\vec{m}_{i}(t+1)=\vec{m}_{i}(t)+\lambda(t) * h_{b, i}(t) *\left(\vec{x}(t)-\vec{m}_{i}(t)\right)
$$

where $\lambda$ is the learning rate which is chosen between 0 and 1 at the beginning and which is logarithmically decreased with increasing iteration number $t$. Equation (3) represents a weighted change of the model vectors into the direction of the data vector. The weighting is controlled by the learning rate, and by the Gaussian neighborhood function centered at the winning neuron (Figure 2b):

$$
h_{b, i}(t)=\exp \left(-r_{b, i}^{2} /\left(2 \sigma^{2}(t)\right)\right)
$$

$r_{b, i}$ is the distance between the winning neuron $b$ and the processed neuron $i$. The width of the Gaussian (parameter $\sigma$ ) is approximated as two third of the largest side of the Kohonen layer for the first iteration, and is decreased logarithmically during training. The algorithm converges after a number of iterations. This number is several times larger than the quantity of data vectors [Kohonen, 1995].

The trained Kohonen layer is used to classify all data vectors (Figure 2c). This includes visualization of neighborhood relationships and cluster definition at the trained SOM, classification for each data vector and re-mapping onto the depth section. Here, the total gradient $\left|\nabla \vec{m}_{i}\right|$ is used to visualize variations of the discrete model vectors at the trained SOM:

$$
\left|\nabla \vec{m}_{i}\right|=\sqrt{\left(\partial \vec{m}_{i} / \partial x\right)^{2}+\left(\partial \vec{m}_{i} / \partial y\right)^{2}}
$$

The index $i$ refers to the position of the processed neuron, while $x$ and $y$ represent the directions parallel to the two sides of the Kohonen layer. Equation (5) reveals contiguous regions at the SOM where the model vectors show only small variations compared with its 
neighbors (small total gradients). These clusters are separated by neurons with strong model vector changes (large total gradients). This analysis is comparable with the widely used Umatrix visualization [Davies and Bouldin, 1979]. The advantage of equation (5) is that common image processing methods are based on total gradients, which can be adopted for the clustering of the SOM. Here, the watershed segmentation algorithm [Vincent and Soille, 1991] was applied to define the clusters and its borders. The principal concept of this method is to systematically flood the valleys of a function (regions with low total gradients) until the watersheds (mountain ridges of the total gradient function) are encountered. Three clusters and their bordering watersheds were determined automatically for the example in Figure 2c.

After the segmentation procedure, the winning neuron is determined for each data vector. A cluster is assigned if the winning neuron falls into a distinct segment at the SOM. The colors encoding the clusters are then plotted at the tomographic depth section for each classified data vector (Figure 2c). The example proves that the SOM approach is able to identify clusters with similar seismic properties despite the noisy input data, and to provide an generalized model. This can be interpreted in terms of major lithological units easier than the continuous parameter distributions of the original tomographic images.

\section{Application to the Mallik Data}

The results of the SOM analysis applied to the Mallik crosshole tomographic data are shown in Figure 3. Based on a CMA of the input data (11,060 grid cells) and comparing test runs, the Kohonen layer was constructed of 25 by 25 neurons. Four clusters were determined automatically by the watershed segmentation algorithm (Figure 3a). Each grid cell was then classified corresponding to the location of the winning neuron at the SOM, and plotted at the depth section using the color code of the assigned cluster (Figure 3b). The results were compared with data from borehole 5L-38, using histograms of the distribution of velocity, anisotropy, and attenuation to characterize the nature of each cluster (Figure 3c). The clusters 
are interpreted as: (1. GHBS - red color) gas hydrate bearing sediments, (2. Sd - yellow color) sand dominated sediments, (3. Sh/Coa - green color) shale and coal interlayering, and (4. Slt -grey) silt dominated sediments.

Cluster 1 corresponds to the GHBS with highest GH concentrations and shows the highest P velocities (2.8-3.6 km/s) and attenuation values (7-13), and a significant degree of velocity anisotropy (8-18\%). The increase of P velocity with GH content is a well-known effect. It is related to substitution of fluids by the solid hydrate phase, and the increase in matrix stiffness by cementation. The increase in attenuation with GH content was also determined from sonic data [Guerin et al., 2005]. A petrophysical model to explain both effects in velocity and attenuation is based on the permeability contrast between the host sediment and the newly formed GH [Chand and Minshull, 2004]. The anisotropy values (8-18\%) are higher than reported from the Blake Ridge [Pecher et al., 2003], where 5\% of anisotropy were related with partial alignments of clay particles within the GHBS. Kumar et al. [2006] prefer a model with vertically oriented GH veins to explain the observed TI along the Hydrate Ridge. These authors found no simple correlation between anisotropy and velocity, and thus not with GH concentration. This is supported by the results from Mallik, because the very high GH concentrations would otherwise be imaged by even much higher anisotropy values. We assume that both horizontally oriented clastic particles and GH growth structures contribute to the observed VTI in Mallik.

The other clusters correspond to major lithological units of the background stratigraphy. Cluster 2 (Sd - yellow) is characterized by the lowest P velocities, anisotropy, and attenuation values and is interpreted as sand lithology. This cluster is mapped in the upper section above and partly in the layer below the GHBS. Cluster 4 (Slt - grey) differs from cluster 2 by having slightly higher velocities, and is mapped in the lower section beneath the GHBS. The increased velocities are consistent with the silty lithology described for this depth level in 
Medioli et al. [2005]. Cluster 3 (Sh/Coa - green) is mapped in the depth range of $990 \mathrm{~m}$ to $1070 \mathrm{~m}$, between the layers of highest GH concentration. Comparing with Medioli et al. [2005] and Henninges et al. [2005] this cluster is related to shale and coal interlayering. Wang [2002] measured P wave anisotropy of 6-33 \% for shales, and over $40 \%$ for coals. These numbers agree very well with the values determined for cluster 3 .

\section{Conclusions}

SOM techniques can be used as a powerful tool for the interpretation of tomographic crosssections, if several petrophysical parameters are imaged coincidentially. The topological projection allows a modelling of the multi-attribute input data onto a 2-D feature map. The total gradient of the discrete model vector distribution is used instead of the common Umatrix [Davies and Bouldin, 1979] to visualize neighborhood relationships at the trained Kohonen layer. This allows to automatically map the clusters with similar seismic signatures by the use of the watershed segmentation algorithm.

The derived seismic P wave signature of the GHBS cluster (increased P velocities, strong anisotropy and attenuation) is new and yields important constraints for the simulation of seismic experiments. They can be used to test petrophysical models describing the microstructures and interaction between grains, GH, and pore fluids. At the larger scale of surface experiments, simulations based on the found properties can be carried out to test observed data, and eventually to develop new concepts for the detection and quantification of GHBS. Anisotropy and attenuation of $\mathrm{P}$ waves are promising parameters which have not been used extensively in GH exploration so far.

\section{Acknowledgements}


The cross-well seismic experiment was funded by the German Ministry of Education and Research (BMBF) within the framework of the GEOTECHNOLOGIEN research initiative. We thank G. Guerin, T. Wonik, and an anonymous reviewer for constructive suggestions.

\section{References}

Bauer, K., C. Haberland, R.G. Pratt, F. Hou, B.E. Medioli, and M.H. Weber (2005a), Raybased cross-well tomography for P-wave velocity, anisotropy, and attenuation structure around the JAPEX/JNOC/GSC et al. Mallik 5L-38 gas hydrate production research well, Geol. Surv. Can. Bull., 585, 21 pp.

Bauer, K., R.G. Pratt, M.H. Weber, T. Ryberg, C. Haberland, and S. Shimizu (2005b), Mallik 2002 cross-well seismic experiment: project design, data acquisition, and modelling studies, Geol. Surv. Can. Bull., 585, 14 pp.

Bily, C., and J.W.L. Dick (1974), Naturally occurring gas hydrates in the Mackenzie Delta, N.W.T., Bull. Can. Pet. Geol., 22(3), 340-352.

Chand, S., and T.A. Minshull (2004), The effect of hydrate content on seismic attenuation: A case study for Mallik 2L-38 well data, Mackenzie delta, Canada, Geophys. Res. Lett., 31, L14609, doi:10.1029/2004GL020292.

Collett, T.S., M.W. Lee, S.R. Dallimore, and W.F. Agenda (1999), Seismic- and well-loginferred gas hydrate accumulations on Richard Island, Geol. Surv. Can. Bull., 544, 357-376.

Dallimore, S.R., and T.S. Collett (2005), Summary and implications of the Mallik 2002 Gas Hydrate Production Research Well Program, Geol. Surv. Can. Bull., 585, 1-36. 
Davies, D.L., and W. Bouldin (1979), A cluster separation measure, IEEE Transaction on Pattern Analysis and Machine Intelligence, 1, 224-227.

Guerin, G., D. Goldberg, and T.S. Collett (2005), Sonic attenuation in the JAPEX/JNOC/GSC et al. Mallik 5L-38 gas hydrate production research well, Geol. Surv. Can. Bull., 585, 9 pp.

Henninges, J., Huenges, E., and Burkhardt, H. (2005), In situ thermal conductivity of gashydrate-bearing sediments of the Mallik 5L-38 well, J. Geophys. Res., 110, B11206, doi:10.1029/2005JB003734.

Klose, C.D. (2006), Self-organizing maps for geoscientific data analysis: geological interpretation of multidimensional geophysical data, Comput. Geosci., 10, 265-277.

Kohonen, T. (1995): Self-organizing maps, Springer, New York.

Kumar D., M.K. Sen, N.L. Bangs, C. Wang, and I. Pecher (2006), Seismic anisotropy at Hydrate Ridge, Geophys. Res. Lett., 33, L01306, doi:10.1029/2005GL023945.

Lorensen, T.D., M.J. Whiticar, T.S. Collett, S.R. Dallimore, and J.A. Doughorty (2005), Complete gas composition and isotopic geochemistry from the JAPEX/JNOC/GSC et al. Mallik 5L-38 gas hydrate production research well: cuttings, core, gas hydrate, and production testing results, Geol. Surv. Can. Bull., 585, 19 pp.

Medioli, B.E., N. Wilson, S.R. Dallimore, D. Pare, P. Brennan-Alpert, and H. Oda (2005), Sedimentology of the cored interval, JAPEX/JNOC/GSC et al. Mallik 5L-38 gas hydrate production research well, Geol. Surv. Can. Bull., 585, 21 pp.

Pecher, A.I., W.S. Holbrook, M.K. Sen, D. Lizarralde, W.T. Wood, D.R. Hutchinson, W.P. Dillon, H. Hoskins, and R.A. Stephen (2003), Seismic anisotropy in gas-hydrate- and gas- 
bearing sediments on the Blake Ridge, from walkaway vertical seismic profiling, Geophys. Res. Lett., 30, 14, 1733, doi:10.1029/2003GL017477.

Pratt, R.G., and C.H. Chapman (1992), Traveltime tomography in anisotropic media, II. application, Geophys. J. Int., 109, 20-37.

Pratt, R.G., F. Hou, K. Bauer, and M. Weber (2005): Waveform tomography images of velocity and inelastic attenuation from the Mallik 2002 crosshole seismic surveys, Geol. Surv. Can. Bull., 585, 14 pp.

Rietbrock, A. (1996), Entwicklung eines Programmsystems zur konsistenten Auswertung grosser seismologischer Datensätze mit Anwendung auf die Absorptionsstruktur der LomaPrieta-Region, Kalifornien, PhD thesis, Ludwig-Maximilian-Universität, Munich, Germany.

Sloan, E.D. (1998), Clathrate hydrates of natural gases, $2^{\text {nd }}$ ed., 705 pp., CRC Press, Boca Raton, Fla.

Thurber, C.H. (1983), Earthquake locations and three-dimensional crustal structure in the Coyote Lake area, central California, J. Geophys. Res., 88, 8226-8236.

Tselentis, G.-A., A. Serpetsidaki, N. Martakis, E. Sokos, P. Paraskevopoulos, and S. Kapotas (2007), Local high-resolution passive seismic tomography and Kohonen neural networksApplication at the Rio-Antirio Strait, central Greece, Geophysics, 72, 4, B93-B106.

Vincent, L., and Soille, P. (1991), Watersheds in Digital Spaces: An Efficient Algorithm Based on Immersion Simulation, IEEE Trans. on Pattern Analysis and Machine Intelligence, 13, No. 6, 583-598. 
Wang, Z. (2002), Seismic anisotropy in sedimentary rocks, part 2: Laboratory data, Geophysics, 67, 5, 1423-1440.

Watanabe, T., Shimizu, S., Asakawa, E., Kamei, R., and Matsuoka, T. (2005), Preliminary assessment of the waveform inversion method for interpretation of cross-well seismic data from the thermal production test, JAPEX/JNOC/GSC et al. Mallik 5L-38 gas hydrate production research well, Geol. Surv. Can. Bull., 585, 13 pp.

Wiersberg, T., J. Erzinger, M. Zimmer, J. Schicks, and E. Dahms (2005), Real-time gas analysis at the JAPEX/JNOC/GSC et al. Mallik 5L-38 gas hydrate production research well, Geol. Surv. Can. Bull., 585, 15 pp.

\section{FIGURE CAPTIONS}

\section{Figure 1:}

Tomographic images of a) P wave velocities, b) anisotropy, and c) attenuation. Sonic log derived P wave velocities and attenuation values [Guerin et al., 2005] are superimposed in a) and c). d) Lithology and gas hydrate saturation at borehole 5L-38 as derived from logging data [Henninges et al., 2005]. The subscripts refer to sand (sd), shale/silt (sh), water (w), hydrate (h), coal (coa), and dolomite (dol) fraction, respectively. Sedimentary units I-VI adopted from Medioli et al. [2005].

\section{Figure 2:}

ANN working flow tested for synthetic data. (a) Tomographic images for a hypothetical crosshole experiment. (b) Unsupervised training is based on random choice of data vectors, determination of the winning neuron, and application of a learning rule affecting the model vectors of the winning neuron and its neighborhood. (c) Total gradient of the model vectors of 
the trained Kohonen layer (upper left part). Watershed segmentation is used for clustering (lower left part). For the final re-mapping, the winning neuron and associated cluster is determined for each data vector and the cluster-related color is used to plot the grid cell at the depth section (right part).

\section{Figure 3:}

ANN analysis of the Mallik data. (a) Watershed segmentation of the total gradient function reveals four clusters: Gas hydrate bearing sediments (GHBS), sand dominated sediments (Sd), Shale and coal interlayering (Sh/Coa), and Silt dominated sediments (Slt). (b) Classification of all tomographic grid cells and re-mapping provides a lithological model. (c) Histograms for $\mathrm{P}$ velocity, anisotropy, and attenuation, revealing the seismic signature of each individual class. 
a) Input models (synthetic)

Distance $(\mathrm{m})$

Distance $(\mathrm{m})$

Distance (m)
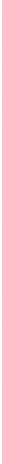

b) Training

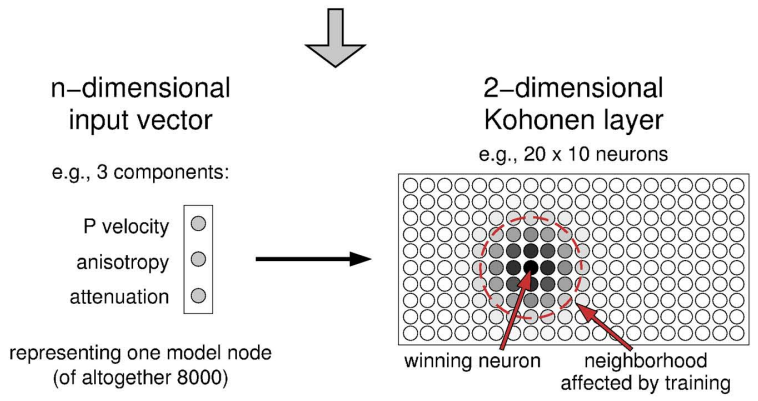

c) Classification/Re-mapping

trained Kohonen layer
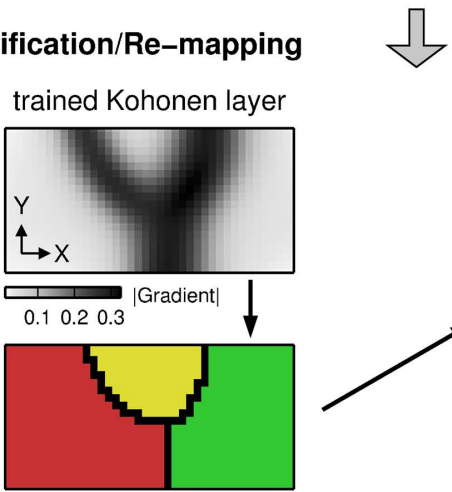

Distance $(\mathrm{m})$

Watershed segmentation

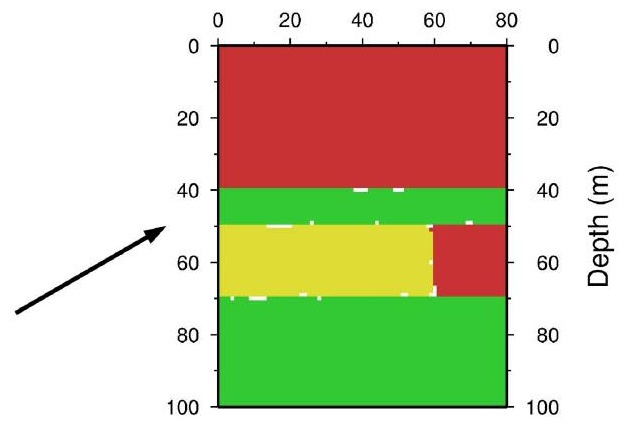


